\title{
Kinetics of degradation of non-recycled and recycled contemporary paper
}

\author{
by Floriana Coppola ${ }^{1 *}$, Alberto Modelli ${ }^{1,2}$, Matija Strlič ${ }^{3}$, Massimo Andretta $^{4}$, Francesco \\ Scagnolari ${ }^{1}$ \\ ${ }^{1}$ Dipartimento di Chimica "G. Ciamician", Università di Bologna, via Selmi 2, 40126 Bologna, Italy \\ ${ }^{2}$ Centro Interdipartimentale di Ricerca in Scienze Ambientali, via S. Alberto 163, 48123 Ravenna, Italy \\ ${ }^{3}$ Institute for Sustainable Heritage, University College of London, Gower Street, London WC1E 6BT, UK \\ ${ }^{4}$ Scuola di Scienze, Università di Bologna, via S. Alberto 163, 48123 Ravenna, Italy \\ *Phone +39 3206337154; E-mail floriana.coppola2@unibo.it
}

\begin{abstract}
Paper is still regarded as the most common carrier of information. Encouraged by environmental policies, the papermaking technology recently changed, resulting in an increased production of recycled paper. Two types of contemporary paper, non-recycled and recycled, were thus investigated to evaluate possible differences in their rate of degradation. The analyses were carried out using unaged paper to evaluate acidity, dry matter and ash content, lignin presence, and fibre furnish. Accelerated ageing experiments were performed at different temperatures $\left(50-80{ }^{\circ} \mathrm{C}\right)$ and water vapour pressures (90.5-227.5 torr). Viscometric measurements were carried out to evaluate the extent of paper degradation as a function of time, upon various accelerated ageing conditions. The results indicate that the rates of degradation follow first-order kinetics with respect to scission of glycosidic bonds, the rate constants for recycled paper being found to be slightly higher than the corresponding constants for non-recycled paper, but comparable within experimental limits. The kinetic constants did not display a monotonic trend with increasing water vapour pressures. The Arrhenius dependence of the rate constants on temperature for both kinds of paper supplied the activation energies, which fall in the typical range expected for paper degradation. Finally, the measured rate constants fit fairly well the recently modelled dose-response function for historic paper. Colour changes were found to be visible to the human eye for samples aged for more than 40 days at 60,70 and $80^{\circ} \mathrm{C}$.
\end{abstract}

Keywords: contemporary paper, recycled paper, kinetics of degradation, accelerated ageing, degree of polymerisation. 


\section{Introduction}

Paper is still regarded as the most widespread information carrier, despite the proliferation of electronic media. Before 1850 paper was mainly made of rag fibres. However, over the last two centuries paper production has significantly changed, with the introduction of wood-derived fibres and new sizing materials. Over the past few decades, there has been a significant increase in the production of paper made from recycled fibres, as encouraged by environmental policies. Over time, elemental chlorine free (ECF) bleaching, based on chlorine dioxide, became the industry standard (Hart and Santos 2013). The share of recycled fibres in paper currently available on the market is generally 50-100\%. Fibre length has become important in the estimation of pulp quality (Čabalovà et al. 2017), especially since Seth (1990) showed that tensile strength is affected by fibre length. The quality of paper made from recycled fibres is generally lower than that of the non-recycled (virgin) material, but the behaviour of different types of pulp can be very variable (Roberts 1996). Currently, the main structural component of modern paper is a felt of cellulose from different origins (such as cotton fibres, groundwood fibres, recycled materials etc.), with the addition of other compounds such as sizing agents, fillers, colourants etc. (Area and Cheradame 2011).

Cellulose is a linear homopolysaccharide, composed of $\beta$-D-glucopyranoside units linked by (1-4) bonds, but its morphological structure in paper is much more complex, and cellulose chains are linked by hydrogen bonds (developing micro- and macrofibrils) (Nevell and Zeronian 1985). In addition to the complexity of the morphological structure of cellulose, other components, such as hemicellulose and lignin, no less relevant to paper degradation, also have complex structures. Several studies (Zou et al. 1996; Barański et al. 2003; Strlič et al. 2007; Łojewski et al. 2010 a) have confirmed that the technical revolution in the papermaking industry, which took place in the middle of the $19^{\text {th }}$ century, has led to a dramatic chemical destabilisation of paper materials. Recent surveys (Barański et al. 2003; Strlič et al. 2005 a) have shown that a significant proportion of archival and library paper (70-85\%) produced between 1850 and 1950 is prone to rapid degradation. It has been shown that papers containing more lignin and ash are generally more sensitive to oxidation and to overall degradation (Lojewski et al. 2010 b; Menart et al. 2011).

Knowledge of the mechanisms of cellulose degradation is a fundamental issue in preventive conservation and management of both historic and contemporary documents. Degradation of paperbased materials is mainly caused by hydrolytic, oxidative and thermal reactions, in which hydrolysis (with scission of the $\beta-1,4-$ glycosidic bonds in cellulose and consequent reduction in chain length) is usually the fastest mechanism, but not the only relevant one (Porck 2000; Barański et al. 2005). Over the last years there has been a growing interest in the adverse effects of indoor conditions on paper- 
based materials, often evaluated using accelerated degradation methods (Barański et al. 2003; Strlič et al. 2005 a). In these, the material is exposed to extreme conditions in terms of temperature, humidity and/or air pollutants, and changes in material properties as a function of time are measured using suitable techniques (Kačík et al. 2009; Strang 2009; Zervos 2010; Strlič et al. 2011).

Viscometry is still the most frequently used technique for the determination of cellulose degree of polymerisation (DP), a measure of the average molar weight. These measurements do not require sophisticated equipment, the procedure is relatively simple and fast, and the method is described in an international standard (ISO 5351 2010). Studies of paper degradation can also be carried out by means of size exclusion chromatography, although this is instrumentally more demanding (Strlič et al. 1998; Emsley et al. 2000; Strlič and Kolar 2003; Dupont and Mortha 2004; Łojewski et al. 2010 a, 2011).

Humidity is one of the most important agents of deterioration, and in the literature it has always been accounted for in terms of relative humidity $(\mathrm{RH} \%)$. The water vapour pressure $\left(\mathrm{P}_{\mathrm{v}}\right)$ associated with a given $\mathrm{RH} \%$, however, increases with increasing temperature (T). For this reason, $\mathrm{P}_{\mathrm{v}}$ instead of $\mathrm{RH} \%$ is considered in the present work as the variable parameter, with the aim to determine separately the effects of $\mathrm{T}$ and $\mathrm{P}_{\mathrm{v}}$.

In the present study, virgin non-recycled and recycled papers were artificially degraded, by exposing the samples to various combinations of $\mathrm{T}$ and $\mathrm{P}_{\mathrm{v}}$ for at least 40 days, in the dark. The samples were then analysed as a function of time, using viscometric measurements to determine the DP. Other techniques (i.e., colourimetry, fibre furnish analysis, phloroglucinol test, residue on ignition and cold extraction) were employed to assess colour changes and characterise the properties of non-degraded paper. The present results focus on the effects of $T$ and $P_{v}$ on the degradation rates of virgin nonrecycled and recycled contemporary paper. In particular, the determination of kinetic constants at different temperatures leads to the calculation of the Arrhenius activation energies. The rate constants for the degradation of contemporary paper are also compared with those of historic paper, for which a dose-response function has recently been modelled (Strlič et al. 2015). 


\section{Experimental}

\section{Materials}

In this study, two kinds of contemporary paper, both manufactured by Fedrigoni S.p.A. (Verona), were analysed:

- Arcoprint 1 EW (A) composed by ECF cellulose (Fedrigoni 2018 a)

- Woodstock (W) composed by $20 \%$ ECF cellulose, and $80 \%$ pre-consumer recycled fibres (Fedrigoni 2018 b).

\section{Paper characterisation}

\section{Acidity}

The cold extraction method modified as suggested by Strlič et al. (2004) was used for pH measurements. The determination of $\mathrm{pH}$ was carried out using a micro-combined glass electrode (Mettler Toledo, InLab ${ }^{\circledR}$ Micro, 51343160). Five determinations for each sample were performed. The $\mathrm{pH}$ values were acquired until a constant reading was obtained. All the $\mathrm{pH}$ values were rounded to the nearest 0.1 decimal digit. The mean uncertainty for alkaline paper was evaluated to be \pm 0.3 (Strlič et al. 2004).

\section{Ash content}

The residue (ash) on ignition at $900{ }^{\circ} \mathrm{C}$ for $1 \mathrm{~h}$ was determined according to the standard procedure ISO 2144 (2015). The ash and water contents were taken into account when calculating the mass of paper samples for evaluation of the DP values.

\section{Viscometry}

The DP was measured viscometrically in accordance with the international standard ISO 5351 (2010). A capillary viscometer (Ubbelohde 53210 I) was used to measure the efflux time of paper dissolved in cupriethylenediamine (CED) solution $0.5 \mathrm{M}$ at $25.0 \pm 0.1{ }^{\circ} \mathrm{C}$, in order to obtain the intrinsic viscosity $[\eta]$. Each DP value was obtained from two samples and two measurements of efflux time were carried out for each sample. [ $\eta]$ values were calculated subtracting the ash content from the dry paper mass. The DP values were calculated using the Mark-Houwink-Sakurada equation (Flory 1953; Tanford 1961) with the set of parameters supplied by Evans and Wallis (1987):

$$
\mathrm{DP}^{0.85}=1.1[\eta] \quad(\text { Eq. 1) }
$$


The uncertainty of DP determinations was evaluated to be about $\pm 3 \%$.

\section{Fibre furnish analysis}

Fibre furnish analysis was performed using the standard procedure ISO 9184-3 (1990). To test the Herzberg reagent, analysis of a pure cellulose sample, Whatman paper No. 1 (Maidstone), as the standard reference was carried out, obtaining the wine-red colour typical of cellulose. Two microscope slides for each kind of paper were prepared and evaluated using an optical microscope in transmission mode (Brunel Microscopes, SP400) equipped with a Canon EOS 1100D camera. A digital microscope (Keyence-VHX 5000) with polarised light was also used in order to identify morphological features of fibres (Ilvessalo-Pfäffli 1995).

\section{Phloroglucinol test}

As an approximate measure of the presence of lignin in the papers, phloroglucinol testing was carried out. Fresh reagent was prepared and stored in the dark (TAPPI T 401 om-82 1982). The phloroglucinol reagent produces a magenta colour in contact with groundwood, partly cooked unbleached chemical pulp, and some other sources of ligneous fibres. Analysis on Whatman paper as the reference was carried out and no colour change was observed.

\section{Colorimetry}

A Minolta CM-2600d spectrometer was used to acquire reflectance spectra with a resolution of $10 \mathrm{~nm}$ and a 3-mm diameter aperture in the $360-740 \mathrm{~nm}$ range. The apparatus is equipped with an internal integrating sphere of 56-mm diameter in reflectance geometry $\mathrm{d} / 8$, and three xenon pulsed lamps. The $\mathrm{D} 65 / 10^{\circ}$ measurement geometry was used (ISO 5631-2 2015). The white calibration plate Minolta CM-A145 was employed. The data were processed with the SpectraMagic ${ }^{\mathrm{TM}}$ NX (Ver. 2.7) software to measure the CIE-L*a*b* colour coordinates. $\mathrm{L}^{*} \mathrm{a} * \mathrm{~b}^{*}$ coordinates were obtained from the average of five scans measured on five different points of each sample. One widely used measure of the colour difference is the CIE 1976, calculated as the Euclidean distance of two points in the CIELAB space: $\Delta \mathrm{E}_{\mathrm{ab}}{ }^{*}=\left(\Delta \mathrm{L}^{* 2}+\Delta \mathrm{a}^{* 2}+\Delta \mathrm{b}^{* 2}\right)^{1 / 2}$.

Additionally, colour changes were also calculated in terms of $\Delta \mathrm{E}_{00}$ with the more recent CIEDE 2000 model (ISO/CIE 11664-6 2014) using the Excel implementation available online (Sharma et al. 2005 a), described by Sharma et al. (2005 b). 


\section{Accelerated Degradation}

The accelerated degradation experiments were performed in closed desiccators in an oven. Glycerol-water solutions at different concentrations were prepared in order to achieve the desired humidity content inside the desiccator (Glycerine Producers' Association 1963). Two kinds of experiments were carried out: the first set with constant $\mathrm{T}$ and changing $\mathrm{P}_{\mathrm{v}}$, the second set keeping constant $\mathrm{P}_{\mathrm{v}}$ and changing $\mathrm{T}$. All degradation tests were carried out over 40-55 days. For any $\mathrm{T}$ and RH combination, 8 samples were degraded in one desiccator with quick sample withdrawals every 56 days. Temperature and humidity were checked throughout the experiments using thermohygrometric dataloggers, which showed that the desired conditions were restored within $2 \mathrm{~h}$ after each opening.

\section{Results and Discussion}

\section{Paper characterisation}

The alkalinity and ash content of the two non-degraded papers were equal within experimental limits, but the initial DP values $\left(\mathrm{DP}_{0}\right)$ of Arcoprint and Woodstock were found to be significantly different (see Table 1).

Table 1. $\mathrm{pH}(\mathrm{n}=5)$, ash content $(\mathrm{n}=3)$, and $\mathrm{DP}_{0}(\mathrm{n}=4)$ values with their standard deviations of unaged Arcoprint and Woodstock papers. $n=$ number of measurements.

\begin{tabular}{l|l|l} 
& Arcoprint & Woodstock \\
\hline $\mathrm{pH}$ & $8.5 \pm 0.2$ & $8.6 \pm 0.1$ \\
\hline ash content (\%) & $12.0 \pm 0.2$ & $12.1 \pm 0.2$ \\
\hline $\mathrm{DP}_{0}$ & $2330 \pm 60$ & $1890 \pm 50$ \\
\hline
\end{tabular}

According to the Herzberg stain method (ISO 9184-3 1990), both papers are mainly made of chemical wood pulp, as indicated by a bluish-violet colour of the fibres. Moreover, the same test led to identification of hardwood (vessels) and softwood (pinoids) fibres in both recycled and nonrecycled paper samples (see Fig. 1). 


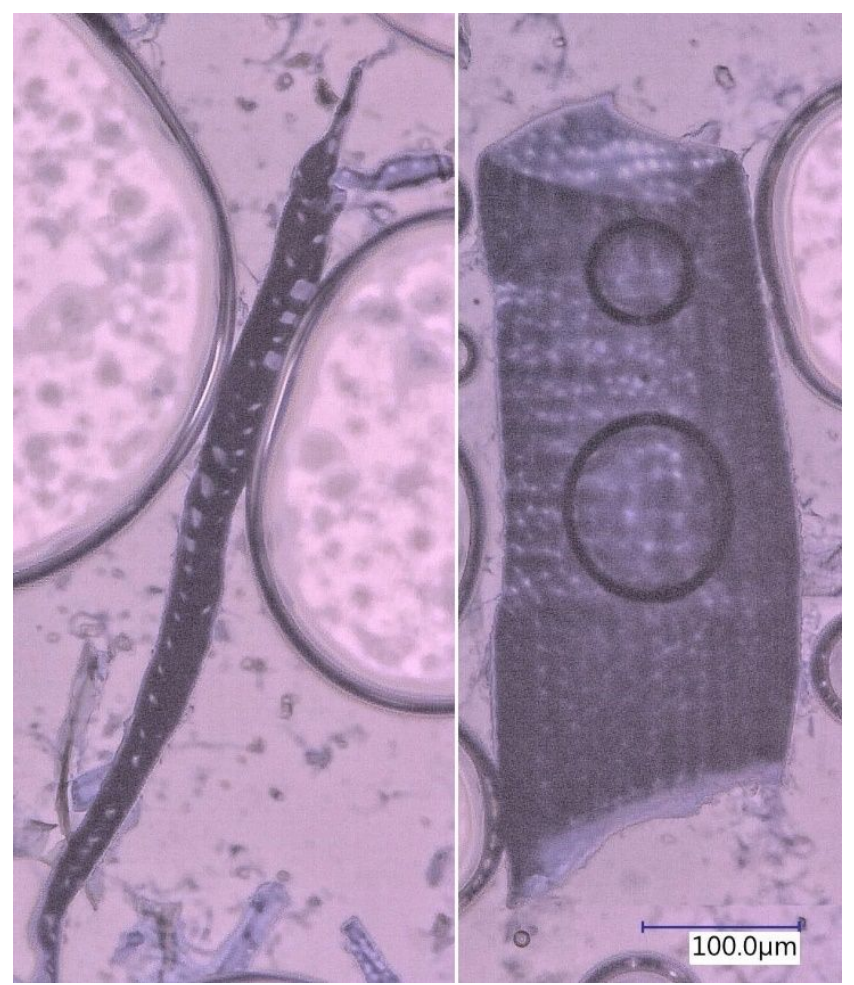

Fig. 1. Digital micrographs: softwood (left) and hardwood (right) fibres are visible. The bluish-purple colour indicates that both papers are made of chemical pulp.

As far as the presence of lignin is concerned, both Arcoprint and Woodstock turned light magenta upon addition of phloroglucinol reagent, indicating a small content of lignin, as expected for delignified chemical pulp. This is important for the viability of viscometry as a method for evaluation of degradation. The standard method (ISO 5351 2010) suggests a content of up to 4\%, although literature (Kačík et al. 2009) showed a good agreement between DP values measured with viscometry and size exclusion chromatography even in newsprint paper mainly made of mechanical pulp, i.e. with a relatively large amount of lignin.

\section{Kinetics of degradation}

The rate of degradation of cellulose is commonly accepted to follow a first order law with respect to the number of glycosidic bonds (Emsley and Stevens 1994; Strlič et al. 2005 b). The rate law can also be described in terms of DP, and provided that the DP value is sufficiently large $(1 / \mathrm{DP}<<1)$ the rate law becomes $d \mathrm{DP} / d \mathrm{t}=\mathrm{k} \mathrm{DP}^{2}$ (Zou et al. 1996), which leads to the integrated equation commonly used to describe the kinetics of paper degradation (Ekenstam 1936):

$$
\frac{1}{\mathrm{DP}}-\frac{1}{\mathrm{DP}_{0}}=\mathrm{kt}
$$


where $\mathrm{DP}$ and $\mathrm{DP}_{0}$ represent the degree of polymerisation of cellulose at time $\mathrm{t}$ and 0 , respectively, and $\mathrm{k}$ is the rate constant. Table 2 summarises the various experimental conditions and gives the rate constants derived from the corresponding plots.

Table 2. Thermo-hygrometric conditions ( $\mathrm{T}, \mathrm{P}_{\mathrm{v}}$ and $\mathrm{RH} \%$ ) for the degradation experiments performed with Arcoprint (A) and recycled Woodstock (W) paper, and evaluated rate constants $\left(\right.$ day $\left.^{1}\right)$ and the corresponding correlation coefficients $\left(\mathrm{R}^{2}\right)$.

\begin{tabular}{|c|c|c|c|c|c|}
\hline Paper sample & $\mathrm{T}\left({ }^{\circ} \mathrm{C}\right)$ & $\mathrm{P}_{\mathrm{v}}$ (torr) & RH (\%) & $\mathrm{k} \cdot 10^{6}\left(\mathrm{day}^{-1}\right)$ & $\mathrm{R}^{2}$ \\
\hline \multirow{5}{*}{ A } & \multirow{5}{*}{70} & 90.5 & 39 & 3.856 & 0.89 \\
\hline & & 99.8 & 43 & 3.644 & 0.88 \\
\hline & & 146.3 & 63 & 10.199 & 0.98 \\
\hline & & 190.4 & 82 & 8.405 & 0.998 \\
\hline & & 227.5 & 98 & 2.105 & 0.82 \\
\hline $\mathrm{A}$ & \multirow{2}{*}{50} & \multirow{8}{*}{90.5} & \multirow{2}{*}{98} & 0.214 & 0.56 \\
\hline $\mathrm{W}$ & & & & 0.325 & 0.46 \\
\hline A & \multirow{2}{*}{60} & & \multirow{2}{*}{61} & 1.311 & 0.95 \\
\hline $\mathrm{W}$ & & & & 1.673 & 0.98 \\
\hline $\mathrm{A}$ & \multirow{2}{*}{70} & & \multirow{2}{*}{39} & 3.856 & 0.89 \\
\hline $\mathrm{W}$ & & & & 4.083 & 0.97 \\
\hline A & \multirow{2}{*}{80} & & \multirow{2}{*}{26} & 10.511 & 0.97 \\
\hline $\mathrm{W}$ & & & & 9.97 & 0.99 \\
\hline
\end{tabular}

Fig. 2 reports plots of the reciprocal DP versus time for the Arcoprint paper at $70{ }^{\circ} \mathrm{C}$ and 4 different $\mathrm{P}_{\mathrm{v}}$ values. The plots display good linearity, as expected from Eq. 2.

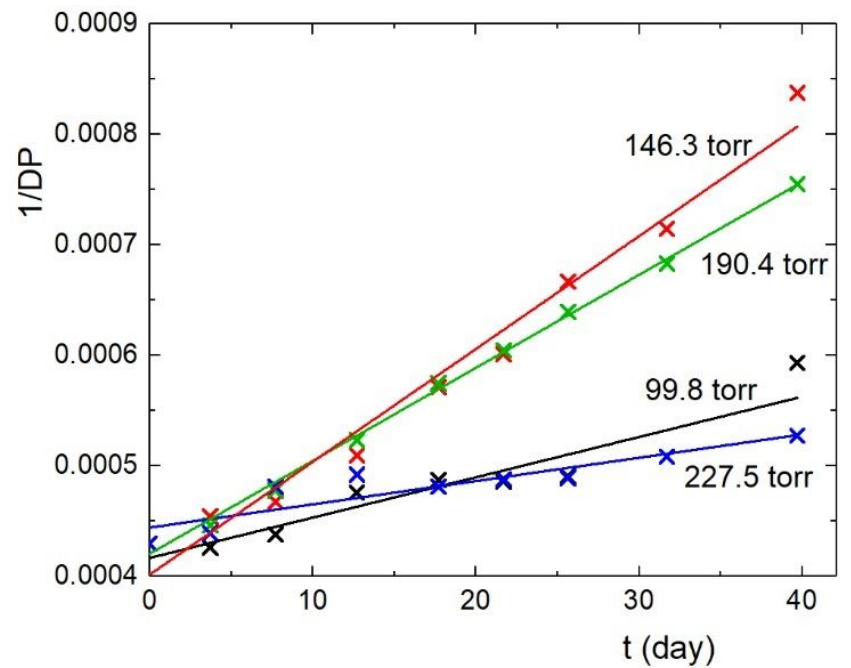

Fig. 2. Reciprocal DP as a function of time for the degradation experiment using Arcoprint paper at constant $\mathrm{T}\left(70{ }^{\circ} \mathrm{C}\right)$ and four different $\mathrm{P}_{\mathrm{v}}$.

The order of magnitude $\left(10^{-6}\right.$ day $\left.^{-1}\right)$ of the kinetic constants is in line with the literature (Zou et al. 1996; Strlič et al. 2015), taking the effects of pH, T and RH\% into account. 
At first glance, Fig. 2 reveals that the slope of the curves does not increase monotonically with $P_{v}$. In particular, Fig. 3 shows the rate constants as a function of $\mathrm{P}_{\mathrm{v}}$, where the trend displays a maximum at intermediate $\mathrm{P}_{\mathrm{v}}$ levels. At $70{ }^{\circ} \mathrm{C}$ the $90.5-227.5$ torr $\mathrm{P}_{\mathrm{v}}$ range corresponds to a 39-98 $\mathrm{RH} \%$ range (see Table 2). Although Zou et al. (1996) found rates of degradation increasing with increasing RH\% for acidic paper, the present results are in line with those reported by Kočar et al. (2005). The latter authors concluded that degradation rates in either dry or highly humid conditions are slower than those occurring at intermediate $\mathrm{RH} \%$ values, the maximum rate being found in the $60-80 \mathrm{RH} \%$ range, for pulps with $\mathrm{pH}>7$. The present results show a maximum rate around $70 \mathrm{RH} \%$, which is consistent with the study by Kočar et al. (2005) as the $\mathrm{pH}$ of our samples was about 8.5. A possible explanation of the rate decrease at high water pressure given by Kočar et al. (2005) was related to the decreasing partial pressure of oxygen with increasing water pressure in the atmosphere, and saturation of paper with water which reduces oxygen diffusion.

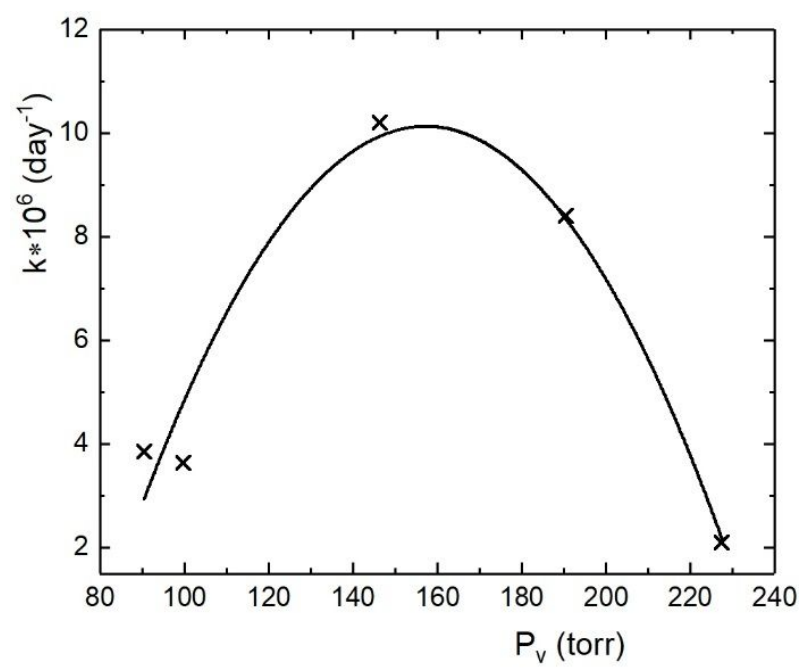

Fig. 3. Rate constants as a function of $\mathrm{P}_{\mathrm{v}}$ found in the degradation experiments carried out using Arcoprint paper at a constant $\mathrm{T}\left(70^{\circ} \mathrm{C}\right)$.

Fig. 4 displays the plots obtained for Arcoprint and Woodstock paper with constant water vapour pressure $\left(\mathrm{P}_{\mathrm{v}}=90.5\right.$ torr $)$ and different temperatures. Good linearity can be observed and as expected the slopes increase with temperature. 

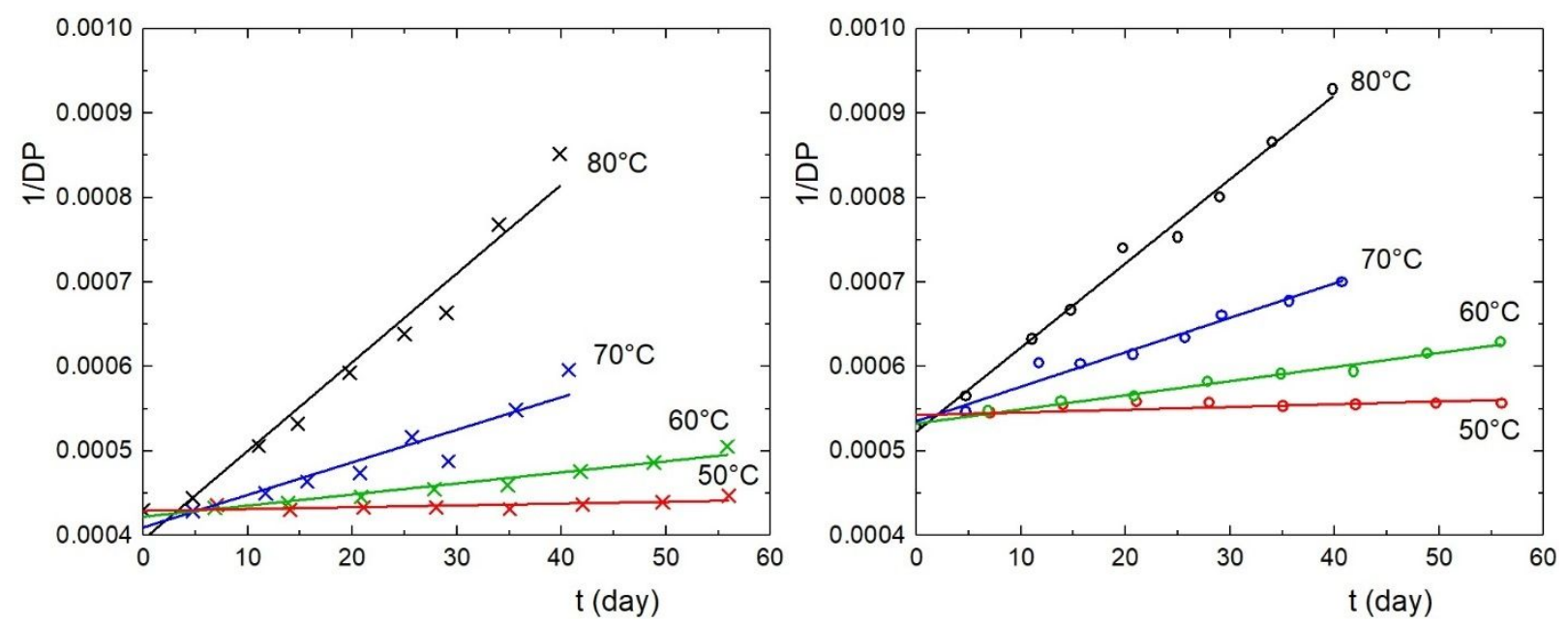

Fig. 4. Reciprocal DP as a function of time for the degradation experiments carried out using Arcoprint (left) and recycled Woodstock (right) paper at constant $\mathrm{P}_{\mathrm{v}}(90.5$ torr) and four different $\mathrm{T}$.

As previously discussed (Zou et al. 1996), the degradation rate of paper follows an Arrhenius dependence on temperature, where $\ln (\mathrm{k})$ is linearly related to $1 / \mathrm{T}$. From the slope of a $\ln (\mathrm{k}) \mathrm{vs}$. 1/T plot it is thus possible to evaluate the activation energy $\left(\mathrm{E}_{\mathrm{a}}\right)$. Arrhenius plots for the Arcoprint and Woodstock paper degradation at a $\mathrm{P}_{\mathrm{v}}$ equal to 90.5 torr are shown in Fig. 5.

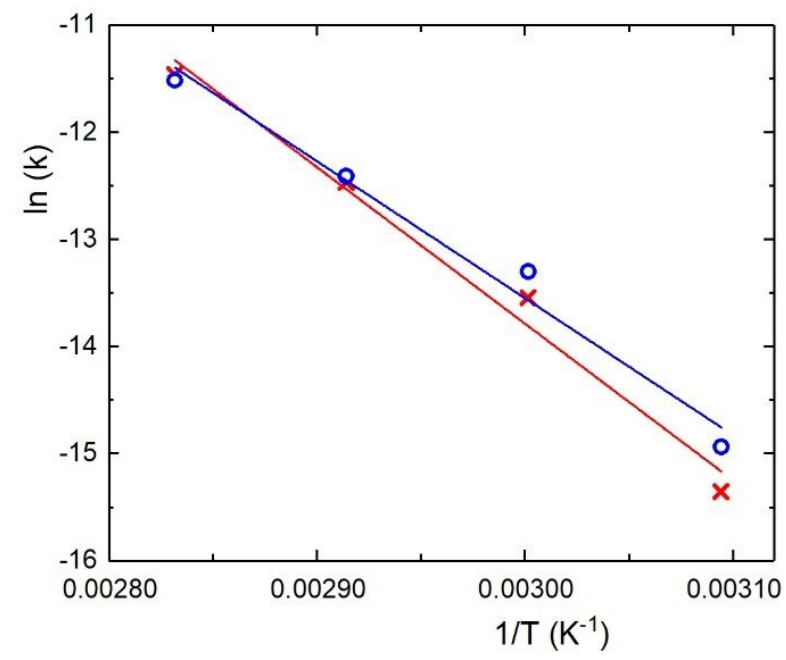

Fig. 5. Arrhenius plots for the rate constants of Arcoprint (crosses) and recycled Woodstock (circles) paper at constant $\mathrm{P}_{\mathrm{v}}$ (90.5 torr).

Good $\ln (\mathrm{k})$ vs. $1 / \mathrm{T}$ linear correlations $\left(\mathrm{R}^{2}=0.98\right)$ are found for both the recycled and nonrecycled paper. The slopes of the plots lead to $E_{a}=121.5 \pm 10.8 \mathrm{~kJ} \mathrm{~mol}^{-1}$ and $106.3 \pm 10.5 \mathrm{~kJ} \mathrm{~mol}^{-1}$ for Arcoprint and Woodstock paper, respectively. The $E_{a}$ of Woodstock is smaller than that of Arcoprint, although they are comparable considering their uncertainties. These $\mathrm{E}_{\mathrm{a}}$ values are similar to those (104-133 $\mathrm{kJ} \mathrm{mol}^{-1}$ ) typically found for hydrolytic degradation of cellulose (Zou et al. 1996; 
Barański et al. 2005; Strlič et al. 2015). However, as recently reported (Rouchon et al. 2016; Liu et al. 2017), there is a substantial variation of the activation energies for degradation of cellulosic materials depending on the conditions of degradation, ranging from 27 to $165 \mathrm{~kJ} \mathrm{~mol}^{-1}$.

It is to be noted that these degradation experiments were carried out with constant $\mathrm{P}_{\mathrm{v}}$, while so far in the literature analogous Arrhenius plots were obtained with constant RH\%. In the present case, $\mathrm{RH} \%$ spans over a wide range of $26-98$, at $\mathrm{T}=50$ to $\mathrm{T}=80^{\circ} \mathrm{C}$. Correspondingly, the moisture content of paper, as evaluated from literature work (Strlič et al. 2015) and originally reported by Paltakari et al. (1996), varies from $1.7 \%$ to $12.4 \%$. According to Zou et al. (1996) this factor significantly affects the pre-exponential factor of the kinetic constant.

A dose-response function describing the dependency of the degradation rate constant on environmental factors and material properties has been recently developed (Strlič et al. 2015). This function has been modelled by taking into account various types of paper with different compositions and manufacturing technologies, but it does not include recycled papers. This dose-response function allows predicting kinetic constants as a function of $\mathrm{T}$ and $\mathrm{RH} \%$ of the environment, and $\mathrm{pH}$ of paper. Fig. 6 displays the scatterplot reported by Strlič et al. (2015) with the results of this study added to it.

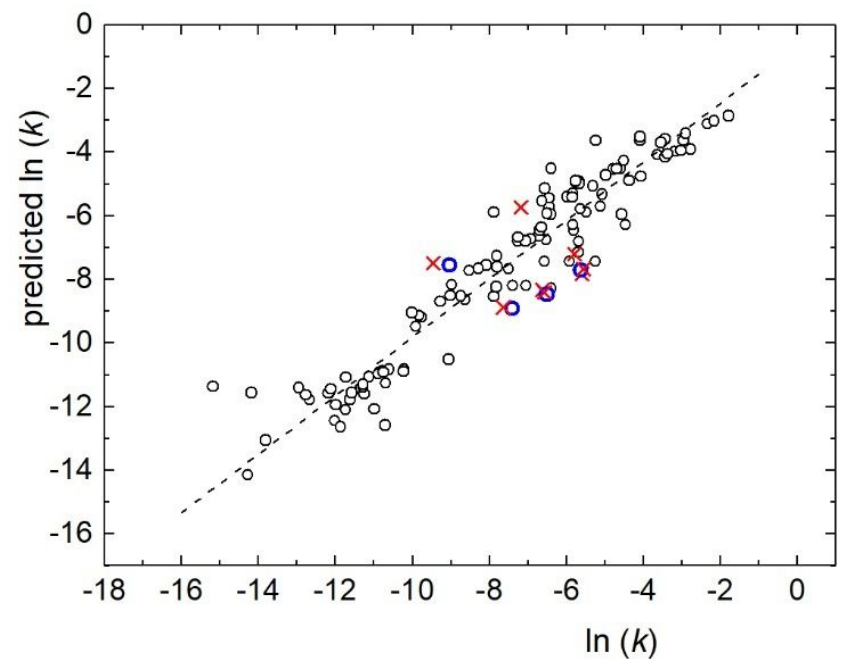

Fig. 6. Comparison between $\ln (k)\left(\right.$ year $\left.^{-1}\right)$ measured in this study and those predicted by the dose-response function (Strlič et al. 2015). The red crosses and the blue circles are associated with Arcoprint and Woodstock paper, respectively.

It can be noted that all the new points are close to the previously reported data, but most of them (nine out of twelve) are placed below the curve, indicating that the kinetic constants measured for the contemporary papers in this study are 4-5 times larger than the corresponding values predicted by the dose-response function. However, in contrast, three points lie above the curve, indicating degradation rates that are lower than the function predicts. It should be noted that these latter three points are associated with the three degradation experiments performed at the highest $\mathrm{RH}(98 \%)$, for which the 
rate constants were found to be lower than those obtained at intermediate RH levels, as pointed out above and described in Fig. 3.

\section{Colour change}

It is well known (Lojewski et al. 2010 b; Castro et al. 2011; Mosca Conte et al. 2012) that degradation of paper affects its colour. Yellowing is ascribed to chromophores in cellulose and lignin polymers (Castro et al. 2011) and, possibly, to photodegradation of optical brighteners. According to spectroscopic and chemical studies, formation of carbonyl groups is responsible for the observed absorption of visible light (Łojewski et al. 2010 b; Mosca Conte et al. 2012). In this work, colour change was calculated in terms of $\Delta \mathrm{E}_{\mathrm{ab}} *$ and $\Delta \mathrm{E}_{00}$. The former has been widely used over the last decades, the latter is more recent and specifically suitable to evaluate yellowing. The interpretation of $\Delta \mathrm{E}_{\mathrm{ab}} *$ values is not straightforward. According to Mahy et al. (1994), the so-called Just Noticeable Difference (JND) is $\Delta \mathrm{E}_{\mathrm{ab}} *=2.3$, while Bicchieri et al. (2016) report that the colour variation appreciated by human eye corresponds to $\Delta \mathrm{E}_{\mathrm{ab}} *=4$. According to Hardeberg (2001) perceptual impact of $\Delta \mathrm{E}_{\mathrm{ab}} *$ is as follows: < 3 hardly perceptible; 3-6 perceptible but acceptable; > 6 not acceptable. The question of what is a perceptible colour change remains open to debate also in $\Delta \mathrm{E}_{00}$ units. According to experiments carried out at the Victoria \& Albert Museum, the threshold for visible perception of colour variation is $\Delta \mathrm{E}_{00}=1.5$ (Ashley-Smith et al. 2002). Table 3 reports the colour coordinates $\mathrm{L}^{*}, \mathrm{a}^{*}, \mathrm{~b}^{*}$ and the colour distance parameters $\left(\Delta \mathrm{E}_{\mathrm{ab}} *\right.$ and $\left.\Delta \mathrm{E}_{00}\right)$ to estimate the colour changes caused on the most aged samples at each temperature.

Table 3. Colour coordinates with standard deviations, $\Delta \mathrm{E}_{\mathrm{ab}}{ }^{*}$ and $\Delta \mathrm{E}_{00}$ determined relative to unaged samples for Arcoprint (A) and Woodstock (W) paper.

\begin{tabular}{|l|l|l|l|l|l|}
\hline & $\mathrm{L}^{*}$ & $\mathrm{a}^{*}$ & $\mathrm{~b}^{*}$ & $\begin{array}{l}\Delta \mathrm{E}_{\mathrm{ab}}{ }^{*} \\
(\mathrm{CIE} 1976)\end{array}$ & $\begin{array}{l}\Delta \mathrm{E}_{00} \\
(\mathrm{CIEDE} 2000)\end{array}$ \\
\hline A (unaged) & $94.41 \pm 0.03$ & $3.05 \pm 0.04$ & $-13.08 \pm 0.12$ & - & - \\
\hline $\mathrm{W}($ unaged $)$ & $93.96 \pm 0.06$ & $1.87 \pm 0.04$ & $-5.29 \pm 0.12$ & - & - \\
\hline $\mathrm{A}\left(\mathrm{T}=50^{\circ} \mathrm{C}\right)$ & $93.86 \pm 0.04$ & $2.67 \pm 0.07$ & $-10.87 \pm 0.19$ & 2.31 & 1.51 \\
\hline $\mathrm{W}\left(\mathrm{T}=50^{\circ} \mathrm{C}\right)$ & $92.81 \pm 0.10$ & $1.62 \pm 0.03$ & $-1.65 \pm 0.17$ & 3.83 & 3.26 \\
\hline $\mathrm{A}\left(\mathrm{T}=60^{\circ} \mathrm{C}\right)$ & $93.35 \pm 0.10$ & $1.95 \pm 0.11$ & $-7.22 \pm 0.34$ & 6.06 & 4.17 \\
\hline $\mathrm{W}\left(\mathrm{T}=60^{\circ} \mathrm{C}\right)$ & $92.70 \pm 0.07$ & $0.92 \pm 0.09$ & $0.94 \pm 0.31$ & 6.43 & 5.75 \\
\hline $\mathrm{A}\left(\mathrm{T}=70^{\circ} \mathrm{C}\right)$ & $92.77 \pm 0.11$ & $1.57 \pm 0.17$ & $-4.66 \pm 0.50$ & 8.70 & 6.23 \\
\hline $\mathrm{W}\left(\mathrm{T}=70^{\circ} \mathrm{C}\right)$ & $92.40 \pm 0.06$ & $0.66 \pm 0.05$ & $2.44 \pm 0.22$ & 7.98 & 7.28 \\
\hline $\mathrm{A}\left(\mathrm{T}=80^{\circ} \mathrm{C}\right)$ & $90.29 \pm 0.02$ & $1.27 \pm 0.09$ & $2.44 \pm 0.32$ & 16.16 & 12.72 \\
\hline $\mathrm{W}\left(\mathrm{T}=80^{\circ} \mathrm{C}\right)$ & $88.95 \pm 0.08$ & $1.11 \pm 0.05$ & $10.38 \pm 0.23$ & 16.47 & 13.92 \\
\hline
\end{tabular}

As expected, in both kinds of paper, the $\mathrm{L}^{*}$ component, which describes the degree of lightness, decreases with ageing, while the $b^{*}$ coordinate, related to the degree of blueness-yellowness, 
increases significantly. The large change in the yellow component, indicated by the $b^{*}$ parameter (see Table 3), for both recycled and non-recycled papers is consistent with oxidation processes and/or degradation of optical brighteners. As far as colour changes are concerned, it turns out that degradation at $\mathrm{T}=50{ }^{\circ} \mathrm{C}$ causes $\Delta \mathrm{E}_{\mathrm{ab}} *$ and $\Delta \mathrm{E}_{00}$ values above the onset of perceptibility only in Woodstock paper. At higher temperatures, the calculated $\Delta \mathrm{E}$ values indicate the occurrence of perceptible colour changes for both types of paper.
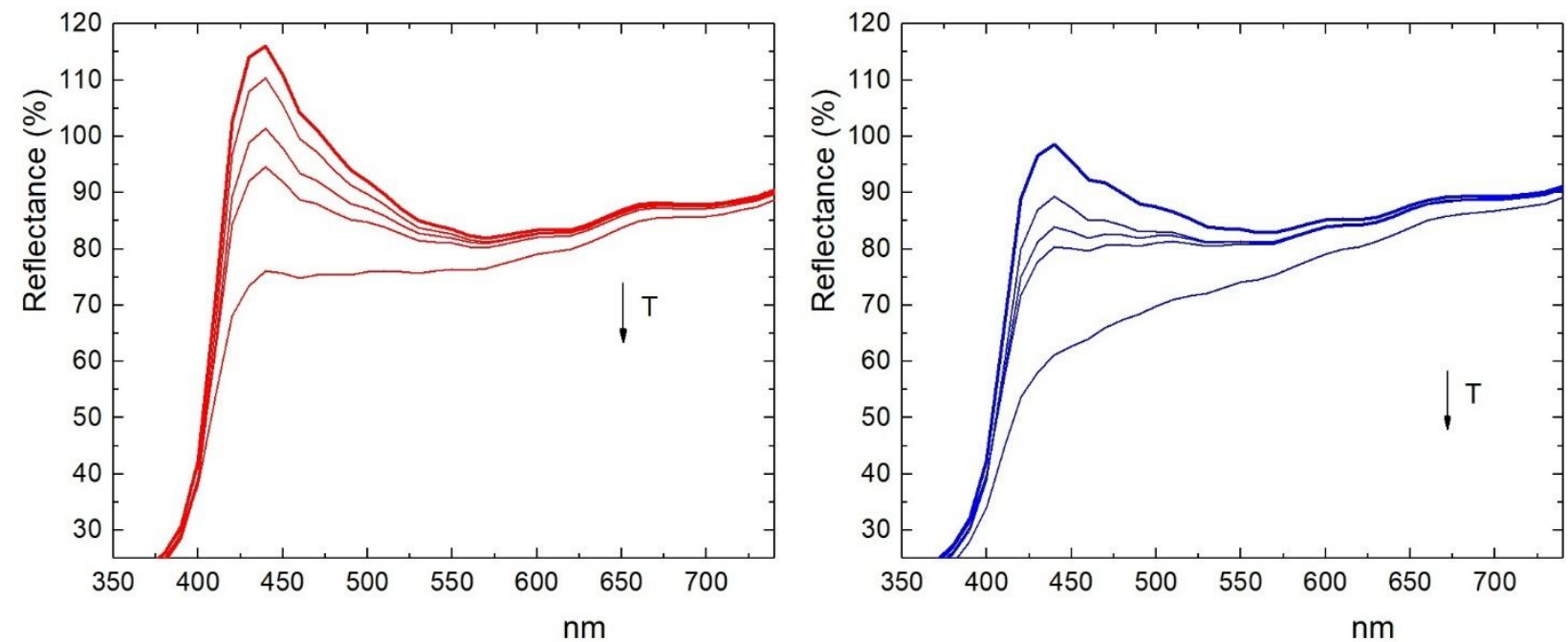

Fig. 7. Visible reflectance spectra of Arcoprint (left) and Woodstock (right) paper at constant $P_{\mathrm{v}}$ (90.5 torr). In both panels, the top (thicker) curve is the spectrum of the unaged sample, followed by the spectra of the most degraded samples at $\mathrm{T}$ $=50,60,70$ and $80{ }^{\circ} \mathrm{C}$.

Moreover, the visible reflectance spectra (see Fig. 7) suggest that both papers, mainly Arcoprint, contain optical brighteners, as indicated by the typical peak at $450 \mathrm{~nm}$ (blue region) in the unaged samples. An evident reduction of the intensity of this peak is observed in the spectra of the samples degraded at various temperatures.

\section{Conclusions}

Accelerated degradation experiments at various temperatures and water vapour pressures were performed to investigate the degradation of contemporary alkaline papers (recycled and nonrecycled). The extent of degradation was estimated using viscometric measurements of the degree of polymerisation (DP), as a function of time. According to $\Delta \mathrm{E}_{\mathrm{ab}} *$ and $\Delta \mathrm{E}_{00}$ values, colour changes are visible $\left(\Delta \mathrm{E}_{\mathrm{ab}} *>3\right.$ and $\left.\Delta \mathrm{E}_{00}>1.5\right)$ for samples of both Arcoprint and Woodstock papers degraded at $60{ }^{\circ} \mathrm{C}$ or higher temperatures. 
The rates of degradation were found to follow first-order kinetics with respect to the number of unbroken gycosidic bonds, and on the basis of Arrhenius dependence of the kinetic constants on temperature the activation energies for the two kinds of paper were calculated. The rate constants for the degradation of recycled paper were found to be somewhat higher than the corresponding constants found for the non-recycled paper, although they are comparable within experimental limits. The activation energy for the recycled paper was found to be somewhat smaller, but again comparable with that found using non-recycled paper. The values found for both kinds of paper fall in the typical range (104-133 kJ/mol) reported in the literature. The present findings do not supply clear indications on the nature (hydrolysis or oxidation) of the prevailing mechanism of degradation.

Interestingly, at constant temperature $\left(70^{\circ} \mathrm{C}\right)$, the kinetic constants were not found to increase monotonically with increasing water vapour pressure, in contrast to previous findings in acidic paper. Actually, the trend displays a maximum around RH 70\% in agreement with literature data, where this trend was ascribed to water saturation of the paper at high humidity content of the atmosphere.

The kinetic constants measured in this work fit fairly well the established dose-response equation that quantitatively describes the dependence of the degradation rate constant on environmental factors and $\mathrm{pH}$ of the paper. The same equation, modelled for historical paper, seems thus to give reliable predictions also for both kinds of contemporary paper considered here.

This study shows that the recycled and non-recycled papers considered degrade similarly. The length and the type of the fibres, the processes in the papermaking and the overall quality of the resulting paper, which can make these two kinds of paper very different from several points of view, seem not to influence their degradation rates. However, further accelerated degradation experiments of a larger variety of recycled and non-recycled virgin samples would be required to confirm the present findings.

\section{Acknowledgements}

The authors thank the Italian Ministero dell'Istruzione, dell'Università e della Ricerca for financial support. Thanks are due to Dr. Irena Kralj Cigić (University of Ljubljana) for ash content measurements. 
Cite as: Floriana Coppola, Alberto Modelli, Matija Strlič, Massimo Andretta, Francesco Scagnolari: "Kinetics of degradation of non-recycled and recycled contemporary paper ", Cellulose 25 (2018) 5337-5347

\section{References}

Area MC, Cheradame H (2011) Paper aging and degradation: recent findings and research methods. BioResources 6:5307-5337. DOI 10.15376/biores.6.4.5307-5337

Ashley-Smith J, Derbyshire A, Pretzel B (2002) The Continuing development of a practical lighting policy for works of art on paper and other object types at the Victoria and Albert Museum, in 13th triennial meeting ICOM Committee for conservation, Rio de Janeiro, vol. I, 3-8.

Barański A, Konieczna-Molenda A, Łagan J, Proniewicz L (2003) Catastrophic room temperature degradation of cotton cellu lose. Restaurator 24:36-45. https://doi.org/10.1515/REST.2003.36

Barański A, Łagan JM, Łojewski T(2005) Acid-catalysed degradation. In: Strlič M and Kolar J (Ed.s) Ageing and stabilisation of paper, Ljubljana, National and University Library, 85-100.

Bicchieri M, Monti M, Piantanida G, Sodo A (2016) Effects of gamma irradiation on deteriorated paper. Radiat Phys Chem 125:21-26. http://dx.doi.org/10.1016/j.radphyschem.2016.03.005

Čabalovà I, Kačík F, Gojný J, Češek B, Milichovský M, Mikala O, Tribulová T, Ďurkovič J (2017) Changes in the Chemical and Physical Properties of Paper Documents due to Natural Ageing. BioResources 12: 2618-2634. DOI 10.15376/biores.12.2.2618-2634

Castro K, Princi E, Proietti N, Manso M, Capitani D, Vicini S, Madariaga JM, De Carvalho ML (2011) Assessment of the weathering effects on cellulose based materials through a multianalytical approach. Nucl Instrum Methods Phys Res B 269:1401-1410. https://doi.org/10.1016/j.nimb.2011.03.027

Dupont A-L, Mortha G (2004) Comparative evaluation of size-exclusion chromatography and viscometry for the characterisation of cellulose. $J$ Chromatogr A 1026:129-141. https://doi.org/10.1016/j.chroma.2003.11.002

Ekenstam A (1936) Über das Verhalten der Cellulose in Mineralsäure-lösungen, II. Mitteil: Kinetisches Studium des abbaus der Cellulose in Säure-lösungen. Ber Dtsch Chem Ges. 69:553-559.

Emsley AM, Stevens GC (1994) Kinetics and mechanisms of the low-temperature degradation of cellulose. Cellulose 1: 26-56. DOI 10.1007/BF00818797

Emsley AM, Ali M, Heywood RJ (2000) A size exclusion chromatography study of cellulose degradation. Polymer 41:8513-8521. https://doi.org/10.1016/S0032-3861(00)00243-3

Evans R, Wallis A (1987) Comparison of cellulose molecular weights determined by high performance size exclusion chromatography and viscometry, in Fourth International Symposium on Wood and Pulping Chemistry, Paris.

Fedrigoni (2018 a) http://www.fedrigoni.co.uk/papers/arcoprint-1-ew. Accessed 24 January 2018.

Fedrigoni (2018 b) http://www.fedrigoni.co.uk/papers/woodstock Accessed 24 January 2018.

Flory P (1953) Principles of Polymer Chemistry. Cornell University Press, Ithaca, pp. 266-316.

Forney CF, Brandl DG (1992) Control of humidity in small controlled-environment chambers using glycerol-water solutions. HortTechnology 2:52-54.

Glycerine Producers' Association (1963). Physical properties of glycerine and its solutions. Glycerine Producers' Association, London.

Hardeberg JY (2001) Acquisition and Reproduction of Colour Images: Colourimetric and Multispectral Approaches, Dissertation.com, USA. 
Hart PW, Santos RB (2013). Kraft ECF pulp bleaching: A review of the development and use of techno-economic models to optimize cost performance and justify capital expenditures. Tappi J, 12: 19-29.

Ilvessalo-Pfäffli M (1995). Fiber atlas: identification of papermaking fibers. Springer, Berlin.

ISO 9184-3 (1990). Paper, board and pulps — Fibre furnish analysis — Part 3: Herzberg staining test.

ISO 5351 (2010). Pulps - Determination of limiting viscosity number in cupriethylenediamine (CED) solution.

ISO 5631-2 (2015). Paper and board - Determination of colour by diffuse reflectance - Part 2: Outdoor daylight conditions $\left(\mathrm{D} 65 / 10^{\circ}\right)$.

ISO 2144 (2015). Paper, board and pulps - Determination of residue (ash) on ignition at $900{ }^{\circ} \mathrm{C}$.

ISO/CIE 11664-6 (2014). Colorimetry - Part 6: CIEDE2000 Colour-difference formula.

Kačík F, Kačíková D, Jablonský M, Katuščák S (2009) Cellulose degradation in newsprint paper ageing. Polym Degrad Stabil 94:1509-1514. https://doi.org/10.1016/j.polymdegradstab.2009.04.033

Kočar D, Strlič M, Kolar J, Rychlý J, Matisová-Rychlá L, Pihlar B (2005) Chemiluminescence from paper III: the effect of superoxide anion and water. Polym Degrad Stabil 88:407-414. https://doi.org/10.1016/j.polymdegradstab.2004.12.005

Liu Y, Kralj-Cigić I, Strlič M (2017) Kinetics of accelerated degradation of historic iron gall inkcontaining paper. Polym Degrad 42:255-262. http://dx.doi.org/10.1016/j.polymdegradstab.2017.07.010

Łojewski T, Zięba K, Knapik A, Bagniuk J, Lubańska A, Łojewska J (2010 a) Evaluating paper degradation progress. Cross-linking between chromatographic, spectroscopic and chemical results. Appl Phys A 100:809-821. DOI 10.1007/s00339-010-5657-5

Łojewski T, Zięba K, Łojewska J (2010 b) Size exclusion chromatography and viscometry in paper degradation studies. New Mark-Houwink coefficients for cellulose in cupri-ethylenediamine. J Chromatogr A 1217:6462-6468. https://doi.org/10.1016/j.chroma.2010.07.071

Łojewski T, Zięba K, Kołodziej A, Łojewska J (2011) Following cellulose depolymerization in paper: comparison of size exclusion chromatography techniques. Cellulose 18:1349-1363. DOI $10.1007 / \mathrm{s} 10570-011-9562-7$

Mahy M, Eycken L, Oosterlinck A (1994) Evaluation of uniform color spaces developed after the adoption of CIELAB and CIELUV. Color Res Appl 19:105-121. DOI 10.1111/j.15206378.1994.tb00070.x

Menart E, de Bruin G, Strlič M (2011) Dose-response functions for historic paper. Polym Degrad Stabil 96:2029-2039. https://doi.org/10.1016/j.polymdegradstab.2011.09.002

Mosca Conte A, Pulci O, Knapik A, Bagniuk J, Del Sole R, Łojewska J, Missori M (2012) Role of cellulose oxidation in the yellowing of ancient paper. Phys Rev Lett 108:158301/1-5. https://doi.org/10.1103/PhysRevLett.108.158301

Nevell TP, Zeronian SH (1985) Cellulose Chemistry and its applications, Ellis Hordwood Ltd, Chichester: UK.

Paltakari JT, Karlsson MA (1996) Determination of specific heat for dry fibre material. 82nd Annual meeting, Technical Section, CPPA, B117-B120. 
Porck HJ (2000) Rate of Paper Degradation - The Predictive Value of Artificial Aging Tests, Amsterdam: European Commission on Preservation and Access.

Roberts JC (1996) The Chemistry of Paper. Royal Society of Chemistry, Cambridge.

Rouchon V, Belhad O, Duranto M, Gimat A, Massiani P (2016) Application of Arrhenius law to DP and zero-span tensile strength measurements taken on iron gall ink impregnated papers: relevance of artificial ageing protocols, Appl. Phys. A 122:773/1-10. DOI 10.1007/s00339-016-0307-1

Seth RS (1990) Fibre quality factors in papermaking. In: Caulfield DF, Passaretti JD, Sobczynski SF (Ed.s) Material interactions relevant to the pulp, paper and wood industries, San Francisco, CA, USA, Materials Research Society, 125-142.

Sharma G, Wu W, Dalal EN (2005 a) Supplemental test data and excel and matlab implementations of the CIEDE2000 color difference formula. http://www2.ece.rochester.edu/ gsharma/ciede2000/ Accessed 5 June 2018

Sharma G, Wu W, Dalal EN (2005 b) The CIEDE2000 color-difference formula: Implementation notes, supplementary test data, and mathematical observations. Color Res Appl 30:21-30. https://doi.org/10.1002/col.20070

Strang T, Grattan D (2009) Temperature and Humidity considerations for the preservation of organic collections - the isoperm revisited. e-Preservation Science 6:122-128.

Strlič M, Kolar J, Žigon M, Pihlar B (1998) Evaluation of size-exclusion chromatography and viscometry for the determination of molecular masses of oxidised cellulose. J Chromatogr A 805:9399. https://doi.org/10.1016/S0021-9673(98)00008-9

Strlič M, Kolar J (2003) Size exclusion chromatography of cellulose in LiCl/N,N-dimethylacetamide. J Biochem Biophys Methods 56:265-279. https://doi.org/10.1016/S0165-022X(03)00064-2

Strlič M, Kolar J, Kočar D, Drnovšek T, Šelih VS, Susič R, Pihlar B (2004) What is the pH of alkaline paper? e-Preservation Science 1:35-47.

Strlič M, Kolar J, Scholten S (2005 a) Paper and durability. In: Strlič M and Kolar J (Ed.s) Ageing and stabilisation of paper, Ljubljana, National and University Library, 3-8.

Strlič M, Kolar J, Pihlar B (2005 b) Methodology and analytical techniques in paper stability studies. In: Strlič M and Kolar J (Ed.s) Ageing and stabilisation of paper, Ljubljana, National and University Library, 25-44.

Strlič M, Kralj Cigić I, Kolar J, De Bruin G, Pihlar B (2007) Non-Destructive Evaluation of Historical Paper Based on pH Estimation from VOC Emissions. Sensors 7:3136-3145. DOI 10.3390/s7123136

Strlič M, Kralj Cigić I, Možir A, De Bruin G, Kolar J, Cassar M (2011) The effect of volatile organic compounds and hypoxia on paper degradation. Polym Degrad Stabil 96:608-615. https://doi.org/10.1016/j.polymdegradstab.2010.12.017

Strlič M, Grossi CM, Dillon C, Bell N, Fouseki K, Brimblecombe P, Menart E, Ntanos K, Lindsay W, Thickett D, France F, De Bruin G (2015) Damage function for historic paper. Part III: Isochrones and demography of collections. Heritage Science 3:40. DOI 10.1186/s40494-015-0069-7

Tanford C (1961) in Physical Chemistry of Macromolecules. Wiley, NY, pp. 390-412.

TAPPI T 401 om-82 (1982) Test method: Fiber analysis of paper and paperboard.

Zervos S (2010) Natural and accelerated ageing of cellulose and paper: a literature review, in Cellulose: structure and properties, derivatives and industrial uses, Lejeune A, Deprez T Editors, NY, Nova Science Publishers, 155-203. 
Cite as: Floriana Coppola, Alberto Modelli, Matija Strlič, Massimo Andretta, Francesco Scagnolari: "Kinetics of degradation of non-recycled and recycled contemporary paper ", Cellulose 25 (2018) 5337-5347

Zou X, Uesaka T, Gurnagul N (1996) Prediction of paper permanence by accelerated aging I. Kinetic analysis of the aging process. Cellulose 3:243-267. DOI: 10.1007/BF02228805 